vibration-rotation spectra of small molecules containing phosphorus. A rapid and accurate photometric method, based on the reduction of dichromate, was developed for the determination of the excess of zine in zinc oxide. Zinc oxide is of interest as a photoconductor in electrophotographic processes. Measurements were made with a low-frequency torsion pendulum of the dynamic modulus and internal friction of irradiated samples of polytetra. fluoroethylene at temperatures between $-180^{\circ} \mathrm{C}$ and $150^{\circ} \mathrm{C}$ in order to obtain new information about the effects of $\gamma$-radiation. The results indicate that irradiation under high-vacuum conditions produces some random chain scission, but cross-linking also occurs and together with an unusual increase in crystallinity the polymer becomes more rigid and brittle.

The Metallurgy Division was mainly concerned with the investigation of chromium alloys with the object of developing strong high-temperature alloys. Metallographic investigations of the surface-damaged layer on abraded surfaces of germanium previously reported on have been extended to other semiconductors, in particular silicon and indium antimonide. It has been established that an extensive arrangement of cleavage cracks, each associated with an array of dislocations, is a common feature. In indium antimonide, the damaged layer also contained glide dislocations and twins. The general mechanism for abrasion seems to be that a system of cracks develops about the indentation made by the contacting abrasive particles, a fragment of the surface being removed whenever a number of the cracks intersect appropriately. Tests made on single crystals of germanium, polished and then etched with $C P .4$, showed that Griffith cracks did not appear until after the test pieces were stressed. Once the cracks formed they become preferred sites for the nucleation of dislccations and when the cracks reached the critical Griffith size brittle fracture of the material occurred.

A new group was set up in the Physics Division to carry out research, under the supervision of Dr. P. W. A. Bowe, on the physics of lasers. The spatial and spectral coherence of a small ruby laser is being investigated. Pumping efficiency using a high-power $Q$-switch device is also being investigated and a Pockel-cell light switch with a rise time of less than 10 ns has been developed. A long-term programme of research on laser materials with initial emphasis on organic complexes has been initiated. In metrology, a screw-pitch measuring interferometer has been used to measure pitch over a 2 -in. length to an accuracy of $\pm 6 \times 10^{-6}$ in.; new techniques for flatness measurement and for the measurement of large jigs and components have been developed; and the accuracy of the frequency standard has been improved by the installation of a quartz crystal oscillator of the Warner type and a phase tracking recoiver, for comparison. with standard very low frequency transmissions.

Various other investigations and devices described in the annual report include a probe to detect the passage of a pressure front; photoelectric fuse-timing equipment; a rapid action dilatometer, based on the type used at the British Welding Research Association, to obtain continuous cooling transformation diagrams of low-alloy steels using heating and cooling rates appropriate to welded joints; the welding of thin-wall titanium tube; the tearing of textiles; the varnish-holding properties of timbers; and the detection and determination of toxic gases. The report concludes with a list of the various personnel and their status, the publications of, and lectures given by, members of the staff of the Laboratories and the names of the Governmental and other committees on which the establishment is represented.
S. WEINTROUB

\title{
TEXAS INSTRUMENTS, INC.
}

$\mathrm{A}^{\mathrm{T}}$ the annual meoting of Texas Instruments, Inc., on April 22, in Dallas, the president, Mr. P. E. Haggerty, reported on the activities of the company during 1964 and explained the principles and system of management. $\mathrm{He}$ mentioned that key personnel were deliberately and consistently moved from one job category to another and upward from one level of management to the next. During the nineteen years since the Second World War the company had grown to more than 150 times its original size, but it had not been necessary to go outside the company in order to fill any principal managerial position. The demand for highly trained personnel with advanced degrees continues, and if the growth rate of degree personnel-both first degree and higher degree - of 1960-64 is maintained, Texas Instruments will require some 12,000 college-trained personnel by 1974 , including about 750 of Ph.D. status.

New record levels in both sales and products were achieved during 1964. Net sales, which totalled some 327.5 million dollars, were up by 18 per cent, and approximately one-fifth of the sales were from operations conducted outside the United States. The organization for the distribution of industrial supplies expanded its activities into international markets by the establishment of branches in Stuttgart, Germany, and in London. Branches in the United States are in Dallas, Houston, Kansas City, Tulsa and Boston.

Most of the company's products stem from investigations of materials at the fundamental structure-of-matter level, and a great variety of metals and non-metallic elements, including semiconductor materials, are refined and processed before fabrication into electrical or electronic components, or assembly into electronic systems. Zincclad aluminium for rotary-press printing plates, and copper-clad materials with performance characteristics equal to or superior to those of solid copper, were two new developments during 1964. Semiconductor-grade silicon, and silicon-carbide clad parts, were in increased demand, and the company continued to be the main supplier to the U.S. Navy of fabricated nuclear fuel.

More than 200 new semiconductor and electronic com. ponent products were introduced during the year. Transistors for television receivers, and plastic-packaged silicon transistors for low-cost applications, were in growing demand for the industrial and domestic market. Now components for the space and defence industries included an advanced series of silicon planar-epitaxial power transistors, a unique glass silicon rectifier with very high-voltage capability, and super-sensitive silicon-controlled rectifiers of reduced size and weight.

The semiconductor integrated circuit was first introduced in the Texas Instruments Laboratories during 1958, and now 86 standard circuit types are manufactured. A recent order for integrated circuits by North American Aviations Autonetics Division amounts to 11 million dollars. The circuits are to be used for the guidance and control system of the U.S. Air Force Minuteman. II intercontinental ballistics missile. Texas Instruments semiconductor plant at Bedford, England, began the production of monolithic circuits during 1964 and the integrated circuits have been designed for the European six-nation space exploration effort called ELDO-ESRO *, for a new hearing aid, and for several industrial programmes.

During 1962, Texas Instruments introduced, on a limited scalo, a completely new approach to seismic exploration. It consists of the application of statistical communications theory to seismic data processing, and

* European Launcher Development Organization-European Space Research Organization. 
utilizes specially developed field techniques and signalintensifying processes. The method has since been fully demonstrated and evaluated, and in many of the more difficult exploration areas of the United States and Canada it has proved to be an advanced tool for petroleum exploration. Advanced digital seismic data-processing centres have been established in New Orleans, Louisiana, and Midland, Texas, to augment the Dallas centre and to meet increased demands. A fourth centre began operation during January 1965 in Calgary, Alberta, and a fifth is to be opened shortly in London, England. A seismic detection system for perimeter defence in jungle warfare has been

\section{THIN FILM RESEARCH}

$\mathrm{T}$ HE twelfth meeting of the Thin Films Group (formerly the Dielectrics Evaporation Group) was held at Harlow during March 24-25. The Research Laboratories of Associated Electrical Industries and Standard Telecommunication Laboratories, Ltd., acted as joint hosts, and visits were made to both of these. The following papers were read: "Ellipsometry", by Mr. B. H. Clausen (Standard Telecommunication Laboratories, Ltd., Harlow); "Defects in Evaporated Silicon Films", by Mr. D. J. Thomas (Standard Telecommunication Laboratories, Ltd., Harlow); "Nucleation Studies on Freshly Cleaved Crystalline Surfaces", by Mr. D. Stirland (Alan Clark Research Centre, Caswell); "Nucleation and Charge on Glass Substrates", by Dr. R. Hill (Electrical Research Association, Leatherhead); "Lorentz Electron Microscopy: Magnetic Imaging in the Electron Microscope", by Mr. A. Green (International Computers and Tabulators, Stevenage); "Oxidation in a Glow Discharge to Prepare Dielectric Films", by Mr. D. White (Associated Electrical Industries, Research Laboratories, Harlow); "Conduction Processes in Dielectric Films", by Mr. J. Simmons (Standard Telecommunication Laboratories, Ltd., Harlow); "Some Readily Evaporated Semiconducting Compounds", by Dr. J. Zemel (Imperial College of Science and Technology - read by Mr. Juhasz, also of Imperial College); "Initial Stresses in Evaporated Films", by Mr. P. Carpenter (Alan Clark Research Centre, Caswell) and Mr. J. D. Wilcock (Imperial College of Science and Technology).

The theme of this meoting was the study of surfaces with special reference to the early stages of growth in thin films. Perhaps the most interesting new results presented were those of Stirland and Hill, whose papers were to a large extent complementary. In the hope of finding a reproducible surface, which is the dream of every electron microscopist, Stirland has cleaved single rock salt crystals in vacuo and evaporated gold from the same source on to the two faces produced. Topographically, one should be a mirror image of the other apart from damage produced in cleaving. He has used a com. bination of optical microscopy and numbered specimen grids to locate the equivalent aroas on the two faces for electron microscopy. Results showed excellent correspondence of cleavage step and dislocation decoration, but mo exact correlation of nucleation site position along the cleavage steps or on the flat areas in between. Exposure of one of the crystal faces to moist air before deposition showed considerable effects on the decoration pattern produced.

Hill has examined the effects on film structure both of electrons incident from the source and of the application of a d.c. field across the growing film. His micrographs show that both processes can affect the type of nucleation and growth and the number of nucleation sites available. His work was done with gold on glass substrates at pressures of $10^{-8} \mathrm{~mm}$ mercury or better. The use of Hill's technique to prevent stray electrons from the source striking the substrate might perhaps affect some of delivered to the U.S. Marine Corps, and a scheme for geophysical experiments to be carried out on the surface of the Moon under the Apollo programme has been prepared. Mr. E. McDermott, who was co-developer of the seismic reflexion technology which has been applied universally in exploration for petroleum and other mineral deposits, and who was co-founder in 1930 of Texas Instruments' predecessor company, Geophysical Service, retired as chairman of the executive committee of Texas Instruments, Inc., on December 31, 1964, and Mr. Haggerty, president and chief executive officer, has assumed also the office vacated by Mr. McDermott.

Stirland's results on nucleation site correspondence. In order to detect the presence of surface charges on the substrate prior to deposition, a potential probe was applied. This gave, in fact, a very sensitive indication of the beginning of nucleation.

The paper on ellipsometry described a technique which is somewhat unfamiliar to many. Using a collimated beam of elliptically polarized light reflected from the specimen surface, the growth of a thin film can be followed in situ by observing changes in the optical constants. The method can be applied to films immersed in liquids and hence is well suited to investigations of anodic film growth and of corrosion or adsorption processes. Owing to the number of variables involved it is necessary to use computer techniques to obtain calculated curves to which the experimental results are fitted as well as possible.

Lorentz electron microscopy is a highly specialized method for examining the magnetic structure of very thin films. A stream of electrons passing near a region of magnetic inhomogeneity is deflected in such a way as to cause an intensity distribution on the screen which corresponds to the variation in the magnetic structure of the film. This method can reveal not only domain walls but also the fine magnetic structure within the domains, and such applications were described in detail by Green.

Electron microscopy has been applied to the study of stacking faults in 'epitaxially' grown silicon deposited by evaporation and by vapour deposition. The incidence of such faults is greatly increased by the presence of silicon carbide formed from pump oils. It is interesting to see that, according to the workers at the Standard Telecommunication Laboratories, Ltd., the use of a gold silicon alloy to promote epitaxy (see Nielson, S., Nature, 205, 755 ; 1965$)$ increases the liability to form faults in the deposit due to thermal strain.

The difficulty of depositing silicon throws into high relief the ease with which single crystal films of lead sulphide, telluride and selenide (and perhaps of related compounds) can be deposited by evaporation. Measurements on the electrical and optical properties of theso materials by Zemel, and, in particular, of the electronic mobilities, show that tho values obtained approach those of bulk single crystals. (Thus, lead telluride shows a bulk value of 30,000 and a value of 23,000 has been ob. tained for tho film at $77^{\circ} \mathrm{K}$.) Juhasz has examined these films by electron diffraction and was able to show an almost perfect Laue diffraction pattern. Since epitaxy was observed even with lattice-misfit greater than 50 per cent it seems that, for these materials at least, substrate surface state is by far more important than lattice correspondence. This was confirmed by Pashley during the onsuing discussion. Juhasz concluded with a graceful compliment to the pioneering work of Wilman, who demonstrated the epitaxy of these compounds as early as 1938.

The relation between details of films structure as revealed by electron microscopy and the mechanical and 